\title{
A SUBLIMAÇÃO JURÍDICA DA FUNÇÃO SOCIAL DA PROPRIEDADE
}

Rafael Lazzarotto Simioni

As dinâmicas nas relações comunicativas da sociedade contemporânea exigem do Direito a estruturação de um alto grau de complexidade. Para a gestão dos paradoxos criados pelo processo de diferenciação funcional, não há outra alternativa à Política e ao Direito senão fecharem-se comunicativamente em uma base autopoiética, como forma de controle das interferências recíprocas entre eles. Nesse contexto, a função social da propriedade se revela no Direito como uma cláusula geral que possibilita uma conexão comunicativa com a Política da sociedade. Mas para ser possível a observação da forma através da qual ocorre essa conexão comunicativa, há uma exigência teórica de diferenciação funcional do Direito e da Política. Essa diferenciação permitirá observar que a Política transforma, através do Direito, o conflito político em conflito jurídico e isso é o que se denominará sublimação jurídica da função social da propriedade: uma vez positivado em lei, o conflito político deixa de ser político e passa a ser jurídico. Em outras palavras, a competência para a solução do conflito político passa a ser atribuída ao sistema jurídico, onde então as expectativas sociais de acesso à propriedade se generalizam 
simbolicamente. Mas como a função social do Direito não é a prestação material de propriedades, essa simbolização normativa da função social da propriedade acaba mistificando o conflito político através da sua generalização simbólica, conquistada pela utilização do Direito como estrutura de codificação secundária.

A respeito dessa relação parasitária entre Direito e Política (Luhmann, 1994), o que a comunidade científica tem feito na grande massa das publicações foi desviar o foco da observação: ao invés do Direito, observa-se o jurista. As questões críticas da função social da propriedade então se resumem à descrição dos papéis de cada categoria profissional como operadores do Direito, analisando as influências ideológicas nas decisões jurídicas. Então todas as questões giram em torno do seguinte: função social da propriedade de quem, para quem e a mando de quem. Essa tentativa de controle das expectativas de papéis é um assunto inte110 ressante por si só, mas não é suficiente para a descrição de possibilidades futuras diferenciadas e principalmente para a descrição de como o Direito resolve criativamente os seus paradoxos. Por outro lado, a grande massa da doutrina jurídica que não pretende ser crítica, descreve a juridicização da função social da propriedade a partir da tradicional atribuição normativa de direito/dever pelo Estado, conforme a teoria dos direitos subjetivos da matriz neokantiana ${ }^{1}$. "Quem, com quais requisitos, pode o quê?" Assim, a análise (crítica) de papéis permite boas denúncias a respeito do comprometimento ideológico das operações jurídicas. E a análise normativa permite o básico, que é a capacitação do jurista no entendimento dos sentidos possíveis da norma jurídica para uma decisão. Mas nenhum desses posicionamentos epistemológicos permite observar os problemas

1. Utiliza-se aqui a distinção das matrizes epistemológicas do Direito realizada por Rocha (1998, p. 89-100). 
operacionais internos ao sistema jurídico decorrentes da simultaneidade nas conexões que ocorrem entre o Direito e a Política da sociedade. E simultaneidade não significa sincronização, mas sim incontrolabilidade.

A sociedade industrial exigiu do Direito a sua positividade, isto é, exigiu um Direito seguro e ao mesmo tempo modificável para a sua constante adaptação às sempre penúltimas expectativas da sociedade. As conquistas evolutivas da sociedade contemporânea, contudo, exigem mais que isso: exigem uma diferenciação entre o sistema jurídico e o sistema político da sociedade. Tratam-se de dois sistemas sociais altamente complexos, cuja estruturação das respectivas complexidades (auto-organização) forçou uma relação comunicativa simultânea de autonomia operacional e de dependência cognitiva. A função social da propriedade é apenas um dos exemplos desse fenômeno que exige do Direito uma autonomia operacional em relação à Política e, também, uma autonomia operacional da Política em relação ao Direito. Autonomia, contudo, não significa independência.

A questão central deste artigo, portanto, é a forma através da qual ocorrem as relações entre decisões jurídicas e decisões políticas, utilizando-se a idéia de função social da propriedade como mecanismo de verificação empírica das descrições. Nessas condições, objetiva-se a) demonstrar que essa autonomia já existe na práxis do Direito e da Política, bem como b) descrever a forma, no sentido de forma de diferença (Spencer Brown; Luhmann, 1997, p. 60), através da qual o Direito e a Política da sociedade contemporânea se conectam comunicativamente. Em outras palavras, tratase de percorrer as relações comunicativas contemporâneas entre o Direito e a Política da sociedade, descrevendo a forma através da qual a Política e o Direito estruturam, cada um ao seu modo, a sua própria complexidade e, ao mesmo tempo, mantêm-se conectados cognitivamente pelo meio de codificações secundárias. 
Uma segunda etapa será a descrição daquilo que se denominará sublimação jurídica do conflito político, ou seja, a transferência do problema político para o sistema jurídico como meio de simbolização - ou mistificação - de expectativas sociais depositadas na Política que, quando transformadas em lei, transformam o conflito político em um conflito jurídico. Vale dizer: esvaziam o sentido político das expectativas sociais através da sua substituição por um outro sentido formalmente codificado pelo Direito: "quem, sob quais condições, tem direito a quê".

\section{A onipresença dos sistemas da sociedade na sociedade}

Uma primeira questão à operacionalização jurídica da função social da propriedade é a própria ambigüidade do sentido de uma função social da propriedade. O conceito jurídico de propriedade pode ser deduzido do art. 1.228 do Código Civil, como a atribuição normativa de poderes (uso, fruição,

112 disposição e reivindicação) sobre um bem ao titular do direito de propriedade. Uma idéia, portanto, de direito subjetivo. Mas quando o sistema político aprova leis que conectam essa idéia de propriedade à idéia de função social, ocorre uma radical abertura no sentido jurídico da propriedade.

A partir da positivação da função social da propriedade, qualquer decisão jurídica torna-se juridicamente possível, desde que fundamentada. O espaço para a criatividade do jurista se amplia drasticamente e se amplia tanto que as decisões sobre as situações fáticas que configuram o cumprimento da função social, com a distinção das que não configuram esse cumprimento, passam a ser indeterminadas, aleatórias e contingentes. Verdadeiros hard cases (Dworkin, 2002, p. 127). A proliferação do casuísmo jurisprudencial então se torna inevitável no Direito e a possibilidade de posturas críticas um deleite tedioso.

Seria possível então perguntar: qual é a alternativa? Mas parece que após a queda do muro de Berlin não há mais 
alternativas para os alternativos (Warat, 1997, p. 134) e qualquer posicionamento pode ser igualmente justificado juridicamente e perigoso socialmente. Pode-se optar em assumir qualquer papel na sociedade a respeito da propriedade, até mesmo porque a idéia de democracia está obrigada a assumir o paradoxo de escutar as diferentes expectativas sociais e, inclusive, as expectativas de quem não tem expectativas. Vale dizer: o direito de participação política da sociedade deve abranger inclusive o direito de quem não quer participar, de quem decide pela no mans land (Lyotard, 1996, p. 110), desde que seja garantida pelo menos a oportunidade a essa participação.

Uma postura marxista sobre o papel do Direito na manutenção das contradições sociais a respeito da propriedade, por exemplo, leva à síntese da revolução: se o direito de propriedade está moldado pelos interesses dos proprietários, a sua modificação só pode ocorrer na forma de uma revolução. A proposta de Marx (1999), após observar a transição do primado político do sentido da sociedade para a economia, foi a substituição da forma de organização distribuição/planejamento da propriedade segundo categorias de interesse (classes) por uma racionalidade econômica onde o planejamento e a distribuição da produção e da propriedade pudessem variar independentemente dos interesses classistas. No fundo, embora isto não apareça nos textos baseados no marxismo, a dialética marxista ("materialismo histórico") demonstrou, na forma de injustiça social, a impossibilidade do acesso à produção-propriedade continuar a ser condicionado por instâncias de autoridade econômico-hereditariamente legitimadas pelo Direito. Grosso modo, a crítica marxista é, pois, uma crítica às formas estratificadoras e segmentárias de organização social.

Mas a evolução das formas de organização social para sistemas de complexidade mais elevada provocou a dissolução das conexões entre direitos e poder econômico segundo 
classes ou status sociais, e a personalidade jurídica passou a ser atribuída ao ser humano não por sua hereditariedade ou poder econômico, mas através de um novo instrumento distributivo chamado contrato (Luhmann, 1983, p. 25). Ainda que os seres humanos sem poder econômico ficassem fora do sistema contratual, a possibilidade disponibilizada a qualquer ser humano de contratar provocou alterações profundas na forma a partir da qual a sociedade ganhava sentido.

Esse desenvolvimento foi visto por Durkheim (1989) como uma substituição da organização segmentária por uma organização funcionalmente diferenciada. Nesse contexto, o Direito deixa de ser um sistema predominantemente repressivo e inicia um processo de estabelecimento de sanções restritivas, onde os danos seriam indenizados e não mais vingados (Luhmann, 1983, p. 26). A especificação de sistemas sociais então foi algo inevitável: o cálculo dos danos restou condicionado à diferenciação dos sentidos econômicos, políticos,

114 morais etc. Ou seja, a possibilidade de reparação de danos pressupôs uma diferenciação entre as dimensões possíveis da experiência humana. Daí o sentido da ação racional de Weber como uma ação social orientada a fins, que pode assim calcular os seus próprios riscos e que fundamentou as teorias do planejamento e da gestão estratégica contemporâneas ${ }^{2}$.

A diferenciação funcional provocou um considerável aumento de complexidade da sociedade, onde então não restou outra alternativa senão surgirem sistemas sociais parciais, auto-estruturados a partir de um código binário operacional que lhes garante a identidade pela diferença. A identidade do Direito, por exemplo, ainda pode continuar a fundamentar-se em um direito natural ou em um contrato social (Hobbes), numa norma fundamental (Kelsen) ou em interesses (Jhering) ou mesmo em princípios (Hart,

2. Foi Parsons, contudo, quem viu essa relação em Durkheim e Weber, construindo a sua teoria dos sistemas sociais como sistemas estruturalmente funcionais (Parsons, 1964). 
Dworkin). Mas em uma perspectiva pragmático-sistêmica (Luhmann), o Direito só conquista a sua identidade a partir do que ele não é ${ }^{3}$. Uma descrição, portanto, quase niilista no preciso sentido nietzschiano, onde a identidade surge a partir da diferença e não mais a partir de uma fundação exterior (objetiva) ou interior (subjetiva) na estruturação do conhecimento (Varela, 1996). O Direito então passa a ser a diferença entre direito e não-direito e a sua validade pode ser encontrada exatamente nesse "paradoxo constitutivo" (Merleau-Ponty, 2003, p. 133), vale dizer, autoconstitutivo. Nessa perspectiva, uma decisão jurídica é aquela que decide se um evento do ambiente é direito ou não-direito, porque se decidir se um evento do ambiente é lucrativo ou provoca prejuízos, ou se é ecologicamente sustentável ou degradante, ou moral ou imoral, então, respectivamente, a decisão foi econômica, ecológica ou ética, não jurídica.

Nesse posicionamento pragmático-sistêmico (Rocha, 1997), pode-se observar a desnecessidade de uma definição geográfica-espacial do Direito (cartesiana), bem como de uma localização institucional no sentido tradicional (normativo neo-kantiano). O Direito passa a poder ser observado como um sistema da sociedade, disponível às decisões de qualquer sistema de organização ou de consciência. O Direito está em todo lugar, na forma de decisões jurídicas ${ }^{4}$,

\footnotetext{
3. Rocha denomina essa origem co-dependente de "condição constitutiva paradoxal dos sistemas": "Quando falamos em condição constitutiva paradoxal dos sistemas sociais entendemos, então, que estes sistemas usam sua própria diferença sistema/ambiente para se constituírem como sistema. O direito descreve o que é, indicando aquilo que ele não é." (1997, p. 33).

4. Kelsen (2003, p. 46) já havia observado essa onipresença do sistema jurídico na sociedade através da fórmula "uma conduta que não é juridicamente proibida é - neste sentido negativo - juridicamente permitida". Na perspectiva aqui trabalhada, contudo, a onipresença jurídica não é institucional (Estado), mas comunicativa: a onipresença do direito está inclusive nas decisões jurídicas não estatais das organizações empresariais e das pessoas (contratos, constitucionalismo societário, códigos de best pratices da governança corporativa etc., na medida em que calculam os riscos sancionatórios do direito em cada decisão empresarial ou pessoal).
} 
isto é, decisões que decidem a partir do código binário direito/não-direito e os seus limites passam a ser limites tãosomente de sentido. Em outras palavras, o Direito não precisa mais estar na figura do Estado $^{5}$, mas em qualquer decisão que decide com referência ao código direito/não-direito, segundo a adjudicação dos eventos do ambiente nesse código a partir de um programa condicional do tipo "se isso, então isto”. Essas observações cabem também à Economia, à Política, à Ciência, à Religião, à Moral e a todos os demais sistemas autopoiéticos da sociedade. Nessa perspectiva, o que diferencia um sistema da sociedade dos demais não é mais a sua localização geográfica ou institucional, mas sim o sentido autogerado, como propriedade emergente (autopoiética), por suas próprias operações. A onipresença dos sistemas então se desvela a partir da diferença: qualquer um pode, no ambiente da sociedade, participar comunicativamente de qualquer um dos sistemas da sociedade.

116 Cada sistema da sociedade disponibiliza aos demais uma estruturação da complexidade, isto é, uma redução da complexidade que, paradoxalmente, produz uma complexidade própria, estruturada em uma forma binária. Assim, enquanto o Direito estrutura a complexidade do ambiente social na forma direito/não-direito, a Política também se autonomiza em uma forma fechada de dois lados, com valores auto-excludentes: situação/oposição. Na Economia, a diferença entre pagamento/não pagamento é o que dá sentido às operações econômicas e cada sistema da sociedade existe porque suas próprias operações são realizadas a partir de uma base auto-referencial binariamente codificada.

Para um observador, portanto, os sistemas sociais estão onipresentes na sociedade. As estruturas dos sistemas sociais,

\footnotetext{
5. Embora seja possível utilizar-se uma diferenciação centro/periferia, onde então se pode observar o Poder Judiciário como o núcleo das decisões que atualizam o sistema jurídico, bem como em relação à economia, os bancos centrais, e à política, os congressos ou parlamentos.
} 
que reduzem a complexidade produzindo uma complexidade própria, estão disponíveis a qualquer pessoa. Por isso qualquer pessoa pode decidir entre cometer um pecado ou salvar sua alma (Religião), a julgar a conduta de outros como boa ou má (Moral), a decidir respeitar a lei (Direito), a influenciar os outros (Política), a decidir sobre os seus investimentos (Economia) e a decidir sobre a veracidade ou a falsidade de suas percepções (Ciência). E - o que interessa - qualquer pessoa pode tentar vencer a complexidade, calculando os impactos extra-sistêmicos de sua decisão. Assim, do ambiente, qualquer um pode decidir pelo lucro (Economia) e observar se essa decisão é, ao mesmo tempo, jurídica, política, ética, ecológica etc.

É nessa perspectiva de alta complexidade sistêmica, portanto, que se passa a descrever a função social da propriedade como um paradoxo, isto é, a função social sem referências a uma fundação exterior ou interior, renunciando à "ansiedade cartesiana" (Varela et all, 2003, p. 149) por fundamentos a partir dos quais se torna possível a organização do conhecimento.

\section{0 paradoxo da função social}

Uma pergunta ontológica: o que é o social? Quando se pensa ontologicamente em um conceito de sociedade logo vem à mente a idéia de pessoas. Então a sociedade é descrita como o conjunto de pessoas: a sociedade é a soma de pessoas em um determinado território, ou a soma de pessoas sob uma cultura comum, sob um Estado comum (para se falar da sociedade brasileira), sob uma ordem normativa comum... Enfim, trata-se de um conceito que tem na sua base de auto-referência a velha distinção hierárquica todo/ partes, na qual a sociedade é o todo e as pessoas as partes. Pensar a função social da propriedade em uma sociedade composta de pessoas obriga então esse pensamento a aceitar que se trata de quase oito bilhões de pessoas diferentes, 
com culturas diferentes, com opiniões, percepções, manias, mentiras, desejos, morais e expectativas diferentes e - já não se pode negar isto - inclusive contraditórias e altamente instáveis. O "mundo da vida" (Heidegger, 2005), que constitui o pano de fundo da rede de ações comunicativas (Habermas, 2002, p. 95), não permite uma explicação de como a função social da propriedade, nessa perspectiva, produz e reproduz limites simbolicamente generalizados. Não explica os processos através dos quais a função social da propriedade se cristaliza na sociedade como valor ou norma. Mantém o sentido da função social da propriedade sob um símbolo, um mistério, um segredo, na "sombra essencial do não declarado", no invisível da "gramática dessa repetição" (Derrida, 2002, p.13 e 75).

Quando o Direito se depara com uma função social da propriedade, pode-se então já questionar o sentido dessa função, pois se o social é tudo, pode também ser simulta118 neamente o nada (Sartre, 2005, p. 46). Com Habermas chegar-se-ia à estruturação de um consenso na experiência do agir comunicativo (1992, p. 18). Mas as condições ideais de discurso, a partir de onde se possa retirar uma norma válida pelo consenso sobre o melhor argumento, são condições extremante improváveis na sociedade contemporânea ${ }^{6}$. Especialmente em sociedades desiguais como a brasileira. Entre o ideal e o viável há um abismo de diferença e a sociedade brasileira já conhece bem isso na sua experiência de desigualdade social crônica.

Uma sociedade passível de aceitar um sentido simbolicamente generalizado de função social só pode ser uma sociedade composta não de pessoas, mas de comunicações (Luhmann, 1998, p. 20). Essa foi a radical mudança de

6. Porque "Todo consenso descansa en un reconocimiento intersubjetivo de pretensiones de validez susceptibles de crítica, y para ello hay que suponer que los sujetos que actúan comunicativamente son capaces de criticarse recíprocamente." (Habermas, 1988, p. 168). 
perspectiva da Teoria dos Sistemas Sociais Autopoiéticos de Niklas Luhmann: a sociedade é a totalidade da comunicação significativa (Luhmann, 1992, p. 96). Partindo dessa diferenciação sistema/ambiente, as pessoas deixam de fazer "parte" do sistema da sociedade e passam a constituir o seu ambiente. Só assim é possível a participação das pessoas em qualquer um dos sistemas da sociedade através da linguagem. Essa opção metodológica se justifica porque observar a sociedade como o conjunto das ações humanas (com intenções, vontades, necessidades, expectativas) redundaria na distinção todo/partes, em que o todo seria a sociedade e as partes as pessoas, como sujeitos do objeto sociedade e com quase oito bilhões de expectativas diferentes sobre o mesmo objeto. Pode-se questionar, com Heidegger, se "nós nos tornamos tão insignificantes para nós mesmos que carecemos de um papel” (2003, p. 92) na sociedade. Mas a insignificância do sujeito é a sua indiferença em relação à sociedade. Observando então a sociedade como o complexo de comunicações significativas, o sujeito deixa de ser indiferente e passa a ser diferente da sociedade, isto é, conquista uma posição significativa na sociedade.

Nessa perspectiva, pode-se superar alguns "obstáculos epistemológicos" (Bachelard, 1996) e descrever a função social como um paradoxo. Se se perguntar, por exemplo, pela função da função social da propriedade, logo se pode ver que se trata de um paradoxo passível de infinitas multiplicações. De acordo com a Teoria da Forma de Spencer Brown (apud Luhmann, 1997, p. 60), a função social pode ser observada como a diferença da função anti-social. A função é social quando ela não é anti-social. Ocorre aqui uma tecnização do sentido da função social que facilita a indicação do valor positivo (função social) desse paradoxo, em detrimento do valor reflexivo (função anti-social). Essa forma tecnizada explica, por exemplo, a generalização simbólica do sentido da função social como algo bom para a 
sociedade em qualquer situação e contexto. A função social passa a se justificar por si só, como o amor pelo amor, a paixão pela paixão, o dinheiro para fazer mais dinheiro, o poder para produzir mais poder... o social pelo social. Essa tecnização do paradoxo "função social/anti-social" da propriedade permite a facilitação do crossing (Spencer Brown) da forma de diferença, face aos sentidos auto-excludentes e, assim, binariamente codificados.

Mas uma outra tecnização poderia ser também a função social como a diferença da função individual. Observa-se como muda o sentido. No sistema político, ambas tecnizações (social/anti-social e social/individual) teriam sentido, porque a função social como diferença da função anti-social pode ser ligada à doutrina da função do Estado de promoção do bem comum e, logicamente, de repressão do mal comum (o anti-social). E a função social como diferença da função individual também teria sentido, face

120 à doutrina publicista da supremacia do interesse público sobre o particular. Daí o sentido vacilante, na autodescrição do Direito, da função social da propriedade, ora ligada à idéia de bem comum, ora conectada a idéias de solidariedade, com todas as demais conexões que essas duas palavras carregam.

Esses foram os modos através dos quais a Política resolveu o paradoxo da função social da propriedade. Influenciada pelo contexto do Estado de Bem-Estar Social da sociedade européia do pós-guerra, a teoria publicista se contaminou da idéia, pretensamente reflexiva, da função do Estado: o bem comum. Daí o sentido da função social da propriedade, na autodescrição do Direito, aparecer em um sentido normativo (dever-ser) de utilização da propriedade de modo a produzir benefícios à coletividade, isto é, o bem comum. A introdução desse terceiro valor indeterminado e criativo dos "benefícios à coletividade" é o que permitiu a adjudicação dos eventos do ambiente na forma fun- 
ção social/função anti-social. Então essa assimetrização do paradoxo da função social produziu esse terceiro valor dos benefícios. Só assim uma decisão na sociedade pode julgar se uma propriedade beneficia a coletividade (função social) ou a prejudica (função anti-social). Ou ainda, mediante a re-aplicação recursiva dessa forma em si mesma (re-entry), a referência a bem comum/mal comum, bem comum/bem individual, mal comum/mal individual. Essa possibilidade de indicar sentidos diferentes no re-entry da forma de diferença é a prova da reflexidade (Luhmann, 1996, p. 240) do sentido simbolicamente generalizado da função social da propriedade.

Mas essa segunda tecnização (benefícios/prejuízos à coletividade) não foi suficientemente rigorosa para decisões políticas coletivamente vinculantes. Qualquer um pode já questionar se a percepção desses benefícios não passa de um juízo de valor, bastante subjetivo, de uma pessoa ou de um grupo de interesses em mundos particulares. Pode-se questionar também sobre os benefícios econômicos, ecológicos, políticos, científicos da propriedade... Então, quando a doutrina da função social da propriedade a indica como norma de benefício (valor positivo), cai como pressuposto o prejuízo (valor reflexivo) em um novo paradoxo que requer um novo valor indeterminado e criativo. Em outras palavras, uma decisão sobre a função social ou anti-social, conforme o uso da propriedade produza benefícios ou prejuízos à coletividade, resta novamente indeterminada e, por isso, acaba conquistando determinação apenas em casos concretos, isto é, apenas na casuística das decisões políticas orientadas à opinião pública.

Uma importante decisão política a respeito da função social da propriedade foi a Constituição Federal de 1987/88. Essa Constituição positivou a função social da propriedade na lei sob uma forma operacionalizável pelo Direito. Se a norma jurídica a respeito da função social fos- 
se apenas a Declaração dos Direitos Humanos; ou a vaga garantia da função social dos atuais arts. $5^{\circ}$, XXIII, e 170, III, da Constituição Federal de 1988, a indeterminação e a respectiva dimensão decisória para a criatividade casuisticamente determinada estariam garantidas ao sistema jurídico. Mas os arts. 182 e 186 da CF/88 programaram condicionalmente a "função jurídica" da função social da propriedade, isto é, estabeleceram o "quem, sob quais requisitos, pode o quê". Assim, através dessa tradicional operação, qualquer decisão jurídica sobre a função social da propriedade pode diagnosticar juridicamente um evento social e verificar se ele cumpre com os requisitos legais dos arts. 182 e 186 da $\mathrm{CF} / 88$, na forma dos seus respectivos regulamentos ordinários (Lei Federal n. 10.257/2001 - Estatuto da Cidade; e Lei Federal n. 8.629/93 - Reforma Agrária; conforme se trate de imóvel urbano ou $\operatorname{rural}^{7}$ ). Mas se por um lado essa condicionalização jurídica da função social da propriedade

122 retira a dimensão criativa das decisões jurídicas, por outro, se a função social não seguisse esses parâmetros algoritmos, seria apenas uma regra de reflexão do sistema (ou normas programáticas, ou ainda princípios, segundo as teorias constitucionais), como os direitos à dignidade, à moradia, ao trabalho etc., que estão lá positivados na Constituição Federal, mas que, na realidade empírica da sociedade, aparecem como meras metáforas ou instruções para os processos políticos de produção legislativa. Um controle, portanto, reflexivo do sistema jurídico e informativo do sistema político.

Nesse relacionamento intersistêmico - não linear entre as operações jurídicas e políticas a respeito da função

\footnotetext{
7. Além dessas normas jurídicas, a função social da propriedade pode ser encontrada também nos arts. 2.035, § único e 1.228 do Código Civil, na Lei 9.472/97, Lei 8.884/94, Lei 8.171/91 (Política Agrícola), Lei 4.771/65 (Código Florestal Federal), Lei 4.504/64 (Estatuto da Terra), além das leis de parcelamento e uso do solo e inúmeras outras legislações, inclusive estaduais e municipais.
} 
social da propriedade, é que pode ser encontrada a chave primária de algumas possibilidades latentes que se passará a observar.

\section{Função e prestações}

Observou-se que a função social da propriedade repousa sobre um paradoxo que a Política esconde através da doutrina do bem comum. Mas como o próprio bem comum também é um paradoxo, a solução política se satisfaz com a positivação, em leis, dos requisitos da função social. A função social deixa então de ser um conflito político e passa a ser o cumprimento concreto de certos requisitos prescritos em leis. Agora qualquer um pode orientar-se na sociedade, planejando estrategicamente o cumprimento dos requisitos legais da função social da propriedade como meta para evitar as sanções jurídicas cominadas ao descumprimento.

No caso de uma propriedade rural, fica mais ou menos fácil ao proprietário cumprir a legislação ambiental, cumprir a legislação trabalhista e conseguir um parecer positivo do Incra a respeito dos índices de produtividade (art. 186, CF/88). Observando tudo isso e somente isso, o proprietário poderá ficar tranqüilo diante da onipresença do sistema jurídico, ao menos no que concerne à função social da propriedade. $\mathrm{O}$ discurso terrorista dos ruralistas a respeito do MST então perde o sentido, porque segundo o art. 185 da CF/88, só podem ser desapropriadas para a reforma agrária os imóveis rurais (não urbanos) de quem é proprietário de dois ou mais imóveis ou, se o proprietário só tem um imóvel em seu nome, a propriedade deve ter área superior a quinze vezes o módulo fiscal do município ${ }^{8}$. Além disso, a propriedade deve ser improdutiva, conforme parecer técnico do Incra e também não cumprir a função social (infrações ambientais, trabalhistas e produtividade abaixo dos índices

8. Tratam-se, portanto, de imóveis com área entre 500ha a 900ha ou superiores. 
técnicos, que inclusive possui inúmeras exceções previstas na Lei Federal n. 8.629/93).

Como se vê, as normas jurídicas tranqüilizam. Os ruralistas não precisam mais se preocupar, pois só os grandes latifúndios improdutivos são passíveis de desapropriação para a reforma agrária e, principalmente: toda desapropriação está juridicamente condicionada à indenização. Ou seja, ninguém perde patrimônio por desapropriação, porque o Poder Público Federal indeniza, isto é, paga o valor do grande imóvel improdutivo, para ele mesmo oportunizar o cumprimento da função social mediante assentamentos rurais. Do mesmo modo o Município, no caso das ocupações urbanas. E do outro lado desse conflito político, o MST também já pode ficar tranqüilo, pois os seus direitos de acesso à terra já foram politicamente conquistados: estão assegurados agora em lei. E os urbanos também já dispõem de mecanismos jurídicos para cobrar do Município medi124 das capazes de motivar a utilização "social" da propriedade urbana. Abstraindo aqui a possibilidade de estender esse sentido simbolicamente generalizado da função social às propriedades móveis (pensa-se no domínio na Internet, na propriedade de informações genéticas e de conhecimentos tradicionais), resta a pergunta: mas então qual é o problema? Quem pode se queixar?

Esse efeito tranqüilizador da positivação jurídica do conflito político a respeito da função social da propriedade revela a função da função social da propriedade: generalizar simbolicamente - pode-se dizer também "mistificar" - expectativas normativas, distinguindo-as das expectativas cognitivas, isto é, das expectativas que não merecem confirmação e por isso devem ser modificadas ou abandonadas (Luhmann, 1983). Uma vez transformado o conflito político em jurídico, a função que o Direito presta a esse conflito é a de um mecanismo de seleção de expectativas. E como toda seleção é uma distinção, o Direito permite a separação 
dos eventos comunicativos do ambiente para a sua adjudicação na forma direito/não-direito.

Logo se pode ver então que o Direito não produz função social da propriedade. Não é isso que ele pode prestar à sociedade. A função de um sistema é sempre uma autofunção 9 . Do ponto de vista do ambiente, a função do Direito até pode ser observada como uma multifuncionalidade. Pode ser observada como boa/má (julgamento moral), lucro/prejuízo (economia), enfim, o Direito pode cumprir inclusive a função de "ganha pão" dos juristas (Luhmann, s/d, p. 99). Por isso é necessário fazer uma diferença entre identidade funcional e prestações. Aquilo que o Direito cumpre para os outros sistemas são prestações e cada sistema da sociedade observará essas prestações conforme o código próprio de cada sistema. Em relação ao sistema total da sociedade, a função do Direito é confirmar as expectativas sociais que merecem ser confirmadas mesmo diante de frustrações. A função que o Direito pode prestar aos demais sistemas é tão-somente servir de quarentena para os conflitos de expectativas sociais, selecionando as expectativas normativas que merecem confirmação contrafática (direito) e negando as expectativas que não merecem confirmação (não-direito) e que, por isso, devem ser abandonadas ou modificadas sob outra forma binária: norma $/ \operatorname{cognição~}{ }^{10}$.

A forma de diferença "função/prestação" permite observar que a função social, em um contexto jurídico

9. Prigogine (2002, p. 47) demonstrou matematicamente como é possível a um sistema estar submetido à aplicação de operadores diferentes e, mesmo assim, permanecer com sua função invariada.

10. O Direito, como unidade da diferença entre direito/não-direito, tem como o outro lado da forma a cognição. Por isso, todas as expectativas sociais que o Direito não confirma contrafaticamente (expectativas normativas) devem ser abandonadas ou modificadas mediante o aprendizado do caráter não normativo dessas expectativas (expectativas cognitivas). Daí a diferença entre norma/cognição, que cria o sentido do Direito como sistema de generalização simbólica das expectativas normativas e da Ciência como sistema de produção de expectativas de conhecimento (Luhmann, 1996, p. 105). 
(direito/não-direito), pode ser radicalmente diferente da mesma função social em um contexto político, econômico, científico-tecnológico, religioso, ético... A função social da propriedade pode ser inclusive a de servir de cemitério (a desapropriação para instalação de cemitérios municipais, por exemplo), enfim, um lugar onde se possa cair morto. Por isso, do ambiente da sociedade, pode-se apenas determinar normativamente que a função social da propriedade "deve" produzir lucro (Economia), sustentabilidade (Ecologia), salubridade (Saúde), moral (Ética), conhecimento (Ciência) e todas as demais indicações no lado positivo dos códigos operacionais de cada sistema social. Então, apesar da programação condicional do Direito a respeito da função social da propriedade (arts. 182 e 185 da CF) estar mais ou menos conectada a essas prestações, o abismo entre o ideal e o viável parece aumentar a cada sentença. Até porque é impossível, face à autonomia dos sistemas 126 sociais, construir uma relação linear entre a propriedade e todos os sentidos intersistêmicos possíveis na sociedade. Por exemplo, um terreno baldio no centro da cidade pode ser visto como especulação imobiliária, isto é, como descumprimento do sentido econômico da função social da propriedade. Mas esse mesmo terreno baldio pode estar mantendo vivo um ecossistema natural (Ecologia), ainda que nocivo à saúde humana e, por isso, apenas antropocentricamente incorreto.

Como se pode ver, essa dinâmica intersistêmica que existe na idéia da função social da propriedade é mais que um paradoxo limitado a dois valores auto-excludentes (A porque não A), é mais que uma simples contradição (A = não A). Os sentidos gerados na comunicação tornamse autônomos e submetidos à autonomia autopoiética de cada sistema da sociedade. Entre sistemas autopoiéticos existe mesmo uma comunicação sem sentido, um ruído mal sintonizado que só ganha sentido no interior (codi- 
ficado binariamente) do sistema. A função social da propriedade pode ser vista como lícita ou ilícita em um contexto jurídico; lucrativa ou não lucrativa (prejuízo) em um contexto econômico; pecaminosa ou salvadora em um contexto religioso (especialmente no luterano) e assim por diante, conforme o contexto (sistema) a partir do qual se a observa. Na Política, a função social da propriedade ainda ganha outro sentido, na forma de um discurso de situação ou de oposição. Então logo se pode concluir pela impossibilidade de se estabelecer um circuito linear nesse “ciclo infernal” (Morin, 2002, p. 24), pois uma decisão lícita (Direito) não será, necessariamente, uma decisão lucrativa, ecológica etc.

Entre a função e a prestação social da propriedade, o que cai como pressuposto é a própria diferenciação funcional da sociedade. Em outras palavras, não há mais como avançar sem enfrentar a diferença operacional entre o sistema político e o sistema jurídico da sociedade.

\section{Política e Direito}

A grande maioria dos teóricos do Direito, da Política e do Estado, costuma negar a possibilidade de separação dessas dimensões da sociedade em sistemas autônomos. Realmente, as relações entre Direito, Política e Estado são evidentes e bastante imbricadas ${ }^{11}$. A própria idéia de Estado contribui para a indiferenciação entre a Política e o Direito, já que o Estado pode ser descrito através de um conceito simultaneamente jurídico (Estado de Direito) e político (Estado Benfeitor) (Luhmann, s/d, p. 329). Até hoje se podem formu-

11. Segundo Neves (1994, p. 265), o Direito no Brasil não aceita a teoria da autopoiese porque não há como, aqui, identificar a identidade do sistema, posto estar muito imbricado com a Economia e com a Política, ocorrendo então não um problema de falta de abertura cognitiva, mas de fechamento operacional, falando então de alopoiese ao invés de autopoiese. Zymler (2002, p. 69), contudo, critica Neves observando que a diferenciação entre alopoiese e autopoiese perde o sentido de acordo com o gradualismo autopoiético de Teubner (1997). 
lar proposições sobre o Estado como uma ordem política juridicamente controlada e, ao mesmo tempo, uma ordem jurídica politicamente adaptada às constantes modificações da sociedade. A observação de segunda ordem, contudo, permite ver que se trata de sistemas autopoiéticos e, por isso, operativamente fechados em um código binário específico. A mirada da observação às operações comunicativas (decisões) que são autoproduzidas em cada um desses sistemas comprova a diferença radical que existe entre uma decisão política, uma decisão jurídica e um sistema de organização como o Estado.

O pensamento medieval sequer pôde separar o Estado da Religião, do Direito e da Moral. Talvez tenha sido Hume quem iniciou o questionamento dessa indiferenciação ao refletir sobre os interesses econômicos na propriedade, onde o governo que não protegesse esses interesses poderia sofrer uma oposição justificada (Hume, 2004). Uma

128 oposição, portanto, onde cai como pressuposto a diferenciação de contextos de interesse divergentes e que seria o problema central do Estado moderno: a oposição entre o sistema jurídico e a Política (Luhmann, s/d, p. 330). Assim, o Direito passou a poder ser observado como uma possibilidade de resistência justificada em face do poder político, o que até hoje vigora quando se fala da função da Constituição Federal como instrumento de limitação do poder do Estado em face dos cidadãos: o Estado de Direito. O Estado de Direito então criou o paradoxo de ser uma organização política orientada pelo direito que ele mesmo cria como mecanismo de realização de finalidades políticas. Não houve então outra alternativa senão a diferenciação de dois tipos de atividades "jurídicas" do Estado: uma legislativa e outra jurisdicional, que no entanto faziam, ambas, parte do sistema jurídico (Kelsen, 2003, p. 290). Mas ao mesmo tempo seria absurdo conceber o Direito como mero depositário de decisões políticas e, por outro lado, a limitação 
jurídica do poder político era o modelo da unidade do Estado. Diante desse paradoxo na legitimação do sistema político, duas foram as assimetrizações: a idéia de um direito natural, mais platônico do que religioso, e a de Estado de Direito, para quem já não acreditava mais na legitimidade política de um Estado baseada no direito natural (Luhmann, s/d, p. 333).

De um ponto de vista institucional, essas descrições são racionais e inclusive podem ser verdadeiras. Mas são insuficientes para pretensões teóricas mais sensíveis às dinâmicas da sociedade contemporânea. Se se transladar a observação do Estado de Direito para as operações (decisões) que são produzidas nesse contexto organizacional, logo se torna possível observar decisões com bases auto-referenciais (código) diferentes, com programas diferentes, orientados a comunicações diferentes e com funções também diferentes. O Direito e a Política se tornam autônomos na medida em que cada um deles resolve seus paradoxos por modos diferentes. Enquanto toda decisão política é uma decisão no contexto das alternativas governo/oposição (código operacional), as decisões jurídicas não dependem da orientação política do governo ou da oposição, pois são realizadas sob o código direito/não-direito. Agora, quando um tribunal decide um caso sob códigos estranhos ao Direito, como por exemplo a procedência de uma ação judicial não porque se trata de direito subjetivo do autor, mas porque o autor é amigo, é rico ou pobre, é de situação ou de oposição ou porque é lucrativa etc., então a decisão do tribunal não foi jurídica e ocorreu corrupção ${ }^{12}$.

12. Ocorre corrupção de códigos quando uma instância de decisão competente para produzir operações de um sistema efetua essas operações com base no código operacional de outro sistema. Por exemplo, quando uma decisão jurídica, ao invés de adjudicar os eventos do ambiente sob a forma direito/não-direito, adjudica-os sob outra forma, como lucro/prejuízo (Economia), situação/oposição (Política), verdadeiro/falso (Ciência), bom/mal (Moral) e etc. 
Os programas políticos e jurídicos também são diferentes, pois enquanto a Política adjudica os eventos do ambiente na forma da diferença entre os interesses de situação/interesses da oposição, o Direito realiza a operação (decisão) de distinguir os eventos do ambiente em direito ou não-direito conforme a auto-indicação da legislação (programa). E se se perguntar o que realmente interessa em uma decisão política e em outra jurídica, pode-se ver que a orientação predominante nas decisões políticas é a opinião pública (que faz o controle reflexivo do sistema), enquanto no Direto são os precedentes, a tradição jurisprudencial sobre a mesma matéria.

A função do Direito do ponto de vista da sociedade é a de generalizar simbolicamente expectativas normativas, enquanto que a da Política é a realização de decisões coletivamente vinculantes. Pode-se observar então que o Direito presta uma importante função à Política e vice-versa: o sistema político precisa do sistema jurídico para vincular cole130 tivamente suas decisões através da lei; e o sistema jurídico precisa do político para utilizar a força disponibilizada pelo poder político para a efetividade de suas decisões. O Direito disponibiliza à Política os meios através dos quais o planejamento político pode se tornar coletivamente vinculante de modo claro na forma direito/não-direito; e a Política disponibiliza ao Direito a possibilidade das decisões jurídicas imporem-se pela força politicamente legitimada de modo bastante claro na forma governo/oposição. Trata-se mesmo de uma relação parasitária (Luhmann, 1994), no sentido de Serres (1990, p. 51), onde a Política cresce consumido à ordem jurídica e o Direito cresce consumido à ordem política, sem precisar de uma fundação ontológica externa a essa diferença, isto é, sem precisar de uma norma fundamental, de um consenso, de um direito natural ou mesmo da soberania de um povo como base hierárquica para a sustentação exterior ao próprio paradoxo da legitimação jurídico-política de decisões jurídicas e políticas. 
A Política no Brasil, ao menos a partir da década de 90, tem sido uma política de planejamento: de planejamento econômico, comercial, habitacional, agrário, urbano, cultural, educacional, previdenciário..., enfim, planejamentos setoriais. A Política então reivindica para si o monopólio das decisões coletivamente vinculantes e as institucionaliza pelo meio da comunicação do Direito (as leis) (Luhmann, 1994, p. 94). O planejamento político define objetivos e metas e essas metas são informadas pela Política aos demais sistemas através de leis. Então fica clara a revelação de que um planejamento político na sociedade globalizada, onde as comunicações sociais são muito mais velozes do que a velocidade do planejamento político, implica a necessidade de uma produção legislativa tão veloz quanto a velocidade das flutuações sociais, especialmente as econômicas. As Medidas Provisórias exemplificam esse sintoma de choque na governança, onde a governabilidade pressupõe então uma estrutura de governança tão ágil politicamente quanto legítima juridicamente.

O resultado disso é um sistema jurídico de programações condicionais indeterminadas e aleatórias a casos con$\operatorname{cretos}^{13}$, bem como o contemporâneo fenômeno da judicialização da Política. A Política então desestabiliza o Direito porque, regulamentando antecipadamente as condutas, não oportuniza o tempo necessário ao Direito para se estabilizar semanticamente, nem oportuniza o tempo necessário para o Direito testar os resultados da regulação ${ }^{14}$. E na

13. Daí a contestação ao modelo de Estado de Bem-Estar Social como um modelo inviável economicamente (porque custa muito caro para o Estado garantir os direitos sociais prometidos na Constituição) e que por isso à Política não restou outra alternativa senão diminuir a sua responsabilidade nas prestações sociais, dividindo-a com a iniciativa privada através dos modernos contratos de gestão com as ONG's previstas nas Leis Federais 9.637/98 e 9.790/99.

14. A atividade legislativa, com efeito, altera o direito com mais velocidade do que a jurisdição e a doutrina jurídica podem assimilar. Os próprios mecanismos jurídicos de uniformização da jurisprudência são raramente utilizados, porque sequer há tempo para uma uniformização jurisprudencial. A desigualdade entre a velocidade do tempo da legislação, da jurisdição e da doutrina, no entanto, é um problema interno do Direito, que ele próprio cria enquanto puder solucionar. 
medida em que o planejamento político utiliza, como estrutura de codificação secundária, o meio de comunicação do Direito, a Política cria expectativas sociais de direitos que o Direito é incapaz de efetivar. Especialmente quando essas expectativas pressupõem pagamentos que, diante da autonomia autopoiética dos sistemas da sociedade, não podem ser realizados pelo Direito.

Daí o sentido generalizado, na autodescrição da sociedade brasileira, da Política como um sistema de promessas não cumpridas. E como essas promessas políticas são codificadas secundariamente pelos meios de comunicação do Direito (leis) e da economia (preço), o Direito se revela ineficaz na concretização das promessas políticas e a economia se revela com tendências inflacionárias (Luhmann, 1994, p. 98). Essa política então força a autonomia operacional do Direito através da implementação normativa (legal) de programas políticos orientados teleologicamente a fins espera132 dos pela Política. Mas do ponto de vista interno do sistema jurídico, a produção legislativa também é observada como direito/não-direito. Então, na medida em que os fins dos programas políticos não são atingidos, surge um ciclo de legislação criando legislação em velocidade superior à capacidade de estabilização desses novos programas nas operações jurídicas: a urgência fazendo lei (Ost, 1999). A perversidade, aqui, se revela em extremos: a própria segurança jurídica pode ser observada como comprometida pelo tempo efêmero da urgência na tomada de medidas políticas através do Direito, como também - e paradoxalmente - a própria segurança jurídica pode ser observada já como ameaça à urgência.

Como se vê, ou o Direito se explode em uma tentativa hologramática de internalizar a sociedade global na lei ou ele se implode na tentativa de reproduzir decisões coerentes com base em cláusulas gerais, como a da função social da propriedade. Por isso, não resta outra alternati- 
va ao Direito e à Política senão fecharem-se em uma base auto-referencial como forma de controle das interferências recíprocas entre eles. Esse meio de controle recíproco é o que se denomina Constituição Federal. Esse é o ponto de contato entre o Direito e a Política da sociedade. Através da Constituição Federal, o Direito pode auto-observar a Política a partir da forma direito/não-direito e a Política pode auto-observar os programas jurídicos para o planejamento das articulações entre a situação (governo) e a oposição. A Constituição então funciona como um filtro de complexidade que permite à Política e ao Direito evoluírem em uma relação de interpenetração (Luhmann, 1998, p. 201), onde o compartilhamento de elementos de sentido (acoplamento estrutural) passa a ser o pressuposto comum da identidade autopoiética pela diferença.

\section{Dinâmica da sublimação jurídica do conflito político}

Essas relações entre Direito e Política mereceriam ser mais desenvolvidas, especialmente nas dimensões materiais (sistema/ambiente), temporais (passado/futuro) e sociais (alter/ego $)^{15}$. Mas para os objetivos propostos já é suficiente esta conclusão: a diferenciação funcional entre Direito e Política permite observar que a Política seleciona a comunicação produzida pela opinião pública de modo a tornar possível uma decisão (política) coletivamente vinculante pelo meio de comunicação do Direito (as leis). Essa codificação secundária jurídica utilizada pela Política - as leis - revela como a Política resolve seus problemas políticos: desfazendo-se deles (Luhmann, s/d, p. 338). A Política resolve seus problemas transferindo-os ao Direito. O Direito presta essa função à Política. Entre o direito ou o não-direito (código jurídico), os conflitos entre situação/oposição (código político) se perdem, se sublimam. Os conflitos políticos são

15. Esses desenvolvimentos podem ser observados em Luhmann (s/d, p. 235-350). 
assim sublimados pelo sistema jurídico. Em outras palavras, o Direito despolitiza os conflitos políticos. E qualquer tentativa de politização da justiça corre o risco de corrupção ou de desintegração do sistema jurídico.

O Direito assegura à Política que, uma vez positivadas em leis as suas decisões, os conflitos políticos já não serão mais tratados como conflitos de interesse de situação ou de oposição, mas sim sob critérios exclusivamente jurídicos. Assim, uma vez transformados em lei os conflitos políticos, a Política pode passar a se preocupar com outros problemas. A "bomba" agora está solucionada pela forma direito/nãodireito, isto é, pelo efeito tranqüilizador do "quem, sob quais condições, pode o quê”. Para a verificação empírica disso, basta observar o momento, no processo de decisão política, em que há comemorações pelo término da tarefa: o "sucesso” da decisão política não ocorre na efetivação prática dos direitos criados, mas tão-somente na aprovação da lei que 134 os cria. Em outras palavras, o processo político termina na aprovação da lei e não na sua efetivação. Porque uma vez aprovada a lei, a efetividade passa a ser agora um problema jurídico ou administrativo, para a Política continuar a poder se preocupar com os seus sempre penúltimos problemas.

\section{Considerações finais}

Mas as novas teorizações sobre sistemas de governança, onde a participação popular nas decisões políticas é mais acentuada - até para a repartição das responsabilidades pelos riscos e perigos das conseqüências secundárias das decisões - estão modificando essa relação entre Direito e Política. Os planejamentos políticos habitacionais, por exemplo, estão mais ou menos orientados à idéia da função social da propriedade sem a utilização direta, como meio de comunicação (codificação secundária), do Direito. O meio, nesses planejamentos, é o econômico. A Política, ao menos nesse aspecto da função social da propriedade, está evoluindo para decisões coletiva- 
mente autovinculantes (governança), onde a prestação do Direito é dispensada, ao menos até que surja um conflito no cumprimento de requisitos legais para o direito à habitação. Pode-se observar uma crescente substituição, na Política, do uso coativo do Direito pelo uso persuasivo da economia. Em outras palavras, a Política usa o Direito para legitimar coletivamente suas decisões, mas pode também usar a economia para persuadir negociações coletivas. Mas como toda negociação pressupõe transações, o que pode estar em jogo é o endividamento de quem não tem outra alternativa senão negociar o seu próprio endividamento na política habitacional. Mas esse já é outro problema.

Pode-se então apenas reiterar as vantagens teóricas da observação das operações políticas e jurídicas como operações comunicativas funcionalmente diferenciadas e concluir que as formas de organização social sobre a função social da propriedade são produtos de circunstâncias. E a criatividade requerida pelo paradoxo da função social da propriedade constitui mesmo uma extravagância ${ }^{16}$ que as decisões da sociedade estão obrigadas a realizar para superarem-se a si mesmas. Por mais que a observação tente manipular a forma com a qual os sistemas operam, acoplam ou se organizam, negando a diferença entre Política e Direito, as formas de organização são sempre formas de auto-organização. A observação até pode pretender manipular o ambiente do sistema a partir do qual ela opera, mas o ambiente, como afirmou Foerster, é como ele é (1996, p. 78).

\section{Rafael Lazzarotto Simioni}

é mestre em Direito pela Universidade Caxias do Sul, professor do Departamento de Direito Privado da mesma universidade

16. Extravagância no sentido da criação de uma terceira via paradoxalmente incluída nas duas vias do "entre-deux" de Merleau-Ponty (Ost; Kerchove, 1995, p. 86). 


\section{Referências bibliográficas}

BACHELARD, Gaston. A formação do espírito científico. (Trad. Estela dos Santos Abreu). Rio de Janeiro: Contraponto, 1996.

DERRIDA, Jacques. A escritura e a diferença. (Trad. Maria Beatriz Marques Nizza da Silva). $3^{\text {a }}$ ed. São Paulo: Perspectiva, 2002.

DURKHEIM, Émile. A divisão do trabalho social. (Trad. Eduardo Freitas e Inês Mansinho). $3^{\mathrm{a}}$ ed. Lisboa: Editorial Presença, 1989.

DWORKIN, Ronald. Levando os direitos a sério. (Trad. Nelson Boeira). São Paulo: Martins Fontes, 2002.

FOERSTER, Heinz Von. Las semillas de la cibernética. $2^{\mathrm{a}}$ ed. (Trad. de Marcelo Pakman). Barcelona: Gedisa, 1996.

HABERMAS, Jürgen. De l'éthique de la discussion. (Trad. Mark Hunyadi). Paris: CERF, 1992.

Pensamento pós-metafísico: Estudos filosóficos. $2^{\mathrm{a}}$ ed. (Trad.

Flávio Beno Siebeneichler). Rio de Janeiro: Tempo Brasileiro, 2002.

Teoría de la acción comunicativa I: Racionalidad de la acción y

racionalización social. (Trad. Manuel Jiménez Redondo). Madrid: Taurus Ediciones, 1988.

136 HEIDEGGER, Martin. Os conceitos fundamentais da metafísica: Mundo, finitude, solidão. (Trad. Marco Antônio Casanova). Rio de Janeiro: Forense Universitária, 2003.

. Ser e tempo. Parte I. $14^{a}$ ed. (Trad. Márcia Sá Cavalcante Schuback). Petrópolis: Vozes; São Paulo: Universidade de São Francisco, 2005. HUME, David. Ensaios morais, políticos e literários. (Trad. Anoar Aiex). São Paulo: Nova Cultural, 2004.

KELSEN, Hans. Teoria pura do direito. $6^{a}$ ed. (Trad. João Baptista Machado). São Paulo: Martins Fontes, 2003.

LYOTARD, Jean-François. Moralidades pós-modernas. (Trad. Marina Appenzeller). Campinas: Papirus, 1996.

LUHMANN, Niklas. A nova teoria dos sistemas. BAETA NEVES, Clarissa Eckert e BARBOSA SAMIOS, Eva Machado (Orgs.). Porto Alegre: Ufrgs, Goethe-Institut e ICBA, 1997.

Comunicazione ecológica: Può la società moderna adattarsi alle minacce ecologiche? $3^{\mathrm{a}}$ ed. (Trad. Raffaella Sutter). Milão: Franco Angeli, 1992. El derecho de la sociedad. (Trad. Silvia Pappe, Brunhilde Erker, Luis Felipe Segura, sob a coordenação de Javier Torres Nafarrate). Guadalajara: Universidad Iberoamericana; Barcelona: Anthropos, s/d. - La ciencia de la sociedad. (Trad. Silvia Pappe, Brunhile Erder e Luis Felipe Segura, sob a coordenação de Javier Torres Nafarrate). Guadala- 
jara: ITESO e Universidad Iberoamericana; Barcelona: Anthropos, 1996. LUHMANN, Niklas. Sistemas sociales: lineamientos para una teoría general. (Trad. Silvia Pappe y Brunhilde Erker; sob coordenação de Javier Torres Nafarrate). Barcelona: Anthropos; México: Universidad Iberoamericana, 1998. . Sociologia do Direito I. (Trad. Gustavo Bayer). Rio de Janeiro: Tempo Brasileiro, 1983. . Teoría politica en el Estado de Bienestar. (Trad. Fernando Vallespín). Madri: Alianza Editoral, 1994.

MARX, Karl. O Capital: crítica da economia política. (Trad. Reginaldo Sant'Ana). Rio de Janeiro: Civilização Brasileira, vol. II, 1999.

MERLEAU-PONTY, Maurice. O visível e o invisível. $4^{\mathrm{a}}$ ed. (Trad. José Artur Gianotti e Armando Mora d'Oliveira). São Paulo: Perspectiva, 2003.

MORIN, Edgar. O Método 1: A natureza da natureza. (Trad. Ilana Heineberg). Porto Alegre: Sulina, 2002.

NEVES, Marcelo. "Entre subintegração e sobreintegração: A cidadania inexistente". In: Dados: Revista de Ciências Sociais. Rio de Janeiro: IUPERJ, v. 37, n. 2, 1994.

OST, François; KERCHOVE, Michel van de. Il Diritto ovvero $i$ paradossi del gioco. (Trad. Simona Andrini e Geraldo Lucidi). Milão: Dott. A. Giuffrè, 1995. O tempo do Direito. (Trad. Maria Fernanda Oliveria). Lisboa: Odile Jacob, 1999.

PARSONS, Talcott. The social system. New York: Free Press, 1964.

PRIGOGINE, Ilya. As leis do caos. (Trad. Roberto Leal Ferreira). São Paulo: UNESP, 2002.

ROCHA, Leonel Severo (Org.). Paradoxos da auto-observação: Recursos da teoria jurídica contemporânea. Curitiba: JM, 1997. Epistemologia jurídica e democracia. São Leopoldo: Unisinos, 1998.

SARTRE, Jean-Paul. O ser e o nada: ensaio de ontologia fenomenológica. $13^{\mathrm{a}} \mathrm{ed}$. (Trad. Paulo Perdigão). Petrópolis: Vozes, 2005.

SERRES, Michel. O contrato natural. Lisboa: Instituto Piaget, 1990.

TEUBNER, Gunther. O Direito como sistema autopoiético. (Trad. José Engrácia Antunes). Lisboa: Fundação Calouste Gulbenkian, 1997.

VARELA, Francisco; THOMPSON, Evan; ROSCH, Eleanor. A mente incorporada: Ciências cognitivas e experiência humana. (Trad. Maria Rita Secco Hofmeister). Porto Alegre: Artmed, 2003.

. Conhecer: As ciências cognitivas: tendências e perspectivas.

(Trad. Maria Teresa Guerreiro). Lisboa: Instituto Piaget, 1996.

WARAT, Luis Alberto. Introdução geral ao Direito III: O direito não estudado pela teoria jurídica moderna. Porto Alegre: Safe, 1997.

ZYMLER, Benjamin. Política E̊ Direito: Uma visão autopoiética. Curitiba: Juruá, 2002. 


\section{A SUBLIMAÇÃO JURÍDICA DA FUNÇÃO SOCIAL DA PROPRIEDADE}

RAFAEL LAZZAROTTO SIMIONI

O sentido sociológico da função social da propriedade oscila sobre um paradoxo que as teorias jurídicas e políticas do pós-guerra escondem através da idéia do Estado de Direito e do Estado Benfeitor. A função social da propriedade ilustra esse estágio de desenvolvimento das relações comunicativas entre a Política e o Direito, onde a primeira não tem alternativa senão transferir seus conflitos para o segundo, transformando os conflitos políticos em conflitos jurídicos. Como será visto neste artigo, o resultado dessa sublimação jurídica dos conflitos políticos é a generalização simbólica das expectativas políticas na forma de expectativas normativas, que nessas condições podem ser tranqüilizadas artificialmente pela programação condicional do Direito.

Palavras-chave: Política; Direito; Função Social da Propriedade; Teoria dos Sistemas; Autopoiese.

\section{THE LEGAL SUBLIMATION OF THE SOCIAL FUNCTION OF PROPERTY}

The social function of property oscillates on a paradox that the juridical and political theories of the postwar period hide through the 
idea of the Rule of Law and the Welfare State. The social function of property illustrates that development of the communicative relations between Politics and Law, in which the first transfers its conflicts to the latter, turning political conflicts into legal ones. As it will be seen in this article, the result of that legal sublimation of the political conflicts is the symbolic generalization of the political expectations in the form of normative expectations, so that in those conditions they can be artificially tranquilized by the conditional programming of the Law.

Keywords: Politics; Law; Social Function of Property; Systems Theory; Autopoiesis. 